\title{
Improved pump for transporting liquid feed mixtures through pipes on farms
}

\author{
Oktyabr Rakhimov ${ }^{1 *}$, Sobir Eshev ${ }^{1}$, Mahmud Rakhmatov ${ }^{1}$, Istam Saidov ${ }^{1}$, Furkat \\ Boymurodov $^{1}$ and Iroda Rayimova ${ }^{2}$ \\ ${ }^{1}$ Karshi engineering-economics institute, Kashkadarya, Uzbekistan \\ ${ }^{2}$ Tashkent Institute of Irrigation and Agricultural Mechanization Engineers, Tashkent, \\ Uzbekistan
}

\begin{abstract}
The article substantiates the effectiveness of the use of liquid feed when feeding pigs, shows the advantages of feeding with liquid feed rather than dry feed. It is stated that, when feeding with liquid feed, pigs of some production groups reduce the need for drinking water, while the energy consumption for surviving feed and saliva secretion is reduced to a minimum. The transition to liquid feed mixtures of low moisture content, which include juicy feed or green pastes, is considered rational, but the equipment used for transporting and distributing such feed mixtures requires the improvement of working organs. However, the use of pipeline transport for transporting and distributing feed mixtures on farms and small family farms requires the use of special feed-transporting pumps with high reliability. But, the industry does not produce special pumps for feeding feed mixtures of high concentration with a moisture content of $68 \ldots . .75 \%$, and the use of pumps from other industries does not give effective results. Therefore, the development of a pump used for feeding feed mixtures with low moisture content is very urgent. To solve this problem, the authors have proposed a new energy-saving pump design used for feeding liquid feed mixtures through pipes on farms and small farms. Devices and the principle of operation of the improved pump are given. The novelty of the design is confirmed by the patent of the Republic of Uzbekistan UZ $5149 \mathrm{~B}$.
\end{abstract}

\section{Introduction}

The organization of productive, cost-effective pig breeding on small farms and farms can be successfully solved if it is carried out at a high technical level and the use of rational animal feeding. Feed should be selected according to the diet and prepared in such a way as to meet the energy requirements of animals and ensure their maximum growth [1]. This is possible if the prepared feed contains the following main nutrients: water, nitrogenous compounds, carbohydrates, fats, minerals and vitamins. In the absence or deficiency of at

\footnotetext{
*Corresponding author: rahmat1959@mail.ru
} 
least one of them, the normal growth, development and productivity of animals are disrupted [2,3]. Although individual feed components differ in their composition, none of them can provide a complete percentage of the set of substances necessary for animal feeding. This discrepancy is compensated by feeding several types of feed, selected in the diet. Such feeds make up the following main groups: green fodder plants and canned feed (silage), root tubers and melons, grain and seeds, feed additives (nitrogenous, mineral and vitamin), compound feed (complete and concentrates), food waste. All of these feeds allow you to form a wide range of feeding technologies, which, in turn, determine the type of feeding: concentrate - root vegetable, concentrate - potato, concentrate using food waste. In addition, the feed used for fattening pigs, depending on the ratio of dry feed and water, can be divided into several groups.

Different types of feed consistencies have their own characteristics. Dry food does not require additional preparation, it is convenient for distribution, but it increases the dustiness of the air in the pigsty, losses and causes diseases of the respiratory organs of pigs. When animals are fed only with dry compound feed, their digestibility is reduced by $4 \ldots 6 \%$ compared to the use of wet mash [4].

Feeding with liquid feed has a number of advantages: the time for eating the feed is reduced, the loss of feed is reduced, it becomes possible to use finely ground feed, and the uniformity of the feed and distribution to the feeders are maintained. With a decrease in eat ability in pigs, this method of feeding allows, which is very important, to regulate the nutritional value of feed in the same volume of feed mixture. All this creates conditions for better preservation of livestock and obtaining higher quality pig carcasses.

When feeding with liquid feed in pigs of some production groups [5]. The need for drinking water reduced; the energy consumption for the survival of feed and the secretion of saliva is reduced to a minimum. Warm water is used to prepare liquid feed under appropriate conditions. Warm liquid food better stimulates the appetite and has a beneficial effect on the gastrointestinal tract. Feeding with liquid feed also makes it possible to use one of the most economical and reliable ways of transporting feed - hydro mechanical, that is, a method when feed is distributed to the feeders through pipes in certain doses.

Currently, many pig farms and farms use liquid feed mixtures prepared only from water and compound feed. However, the insufficient amount of compound feed and their high cost restrains the increase in the production of pig products. The use of such traditional feeds as root and tuber crops and combisilos finds less and less, although they are good energy feed [6].

In summer, green forages play an important role in feeding, especially from leguminous grasses. Inclusion of green fodder in balanced diets of pigs in the amount of $10 \ldots 25 \%$ makes it possible to increase the biological value of rations, to obtain a guaranteed level of productivity, biological high-grade meat and to save from 20 to $44 \mathrm{~kg}$ of grain concentrates per 1 centner of weight gain.

All of the above about the consistency of the feed allows us to conclude that the most effective return on the feed will be in the case when feed mixtures are used, which include juicy components or green pastes with low moisture content $(65 \ldots 75 \%)$. Low moisture feed is better eaten and absorbed by animals, increasing their productivity. Due to the use of feed with low moisture content ( $75 \%$ instead of $78 \%$ according to the project), the average daily weight gain of animals can be increased to $20 \mathrm{~g}$. A further decrease in moisture content to $68 \ldots 70 \%$ allows increasing the weight gain of animals to $10 \%$ [7].

The transition to liquid feed mixtures of low moisture content, which include juicy feed or green pastes, is considered rational, but the equipment used for transporting and distributing such feed mixtures requires the improvement of working organs $[8,9,30]$. 
The analysis of the existing technological schemes and means used for the mechanization of the transportation and distribution of feed on pig farms showed that the pressure method for transporting liquid feed mixtures with pumps through pipes can be considered the most perfect. Pipeline transport is highly productive, simple in design, it can be mounted in buildings of any type, it does not require special aft passages, and it combines loading and unloading operations with transportation, regardless of the availability of access roads, and improves work culture.

Science and practice have proven that a pumping unit that feeds liquid feed in pipes directly into the feeders can reduce labor costs by 3 times compared to the delivery and distribution of feed by a mobile feed dispenser [10].

However, the use of pipeline transport for transporting and distributing feed mixtures on farms and small family farms requires the use of special feed-transporting pumps with high reliability. But, the industry does not produce special pumps for feeding feed mixtures of high concentration with a moisture content of $68 \ldots 75 \%$, and the use of pumps from other industries does not give effective results $[11,12,31]$. Therefore, the development of a pump used for feeding feed mixtures with low moisture content is very urgent.

\section{Methods}

A comprehensive literary analysis of the types of feed consistencies has been carried out, the main physics and mechanical properties of feed mixtures affecting the characteristics of the pump were determined according to generally accepted methods with partial changes using well-known devices: viscosity - viscosometers, moisture - by drying a sample of feed sample, concentration of feed mixtures - by selecting a known volume of feed mixtures mixer with subsequent removal of moisture, drying and weighing the dry residue.

\section{Results and Discussion}

To solve the set tasks, we have developed a new energy-saving design of a vane pump with a separator and a screw feeder, which allows transporting feed mixtures of high concentration and low humidity, the novelty of the design is confirmed by the patent of the Republic of Uzbekistan UZ 5149B.

This pump installed on a small-sized unit designed for farms and small farms (farms, family and rental farms) for preparing liquid feed mixtures using feed of our own production, transporting them through pipes and distributing them to feeders. It is highly productive, simple in design, it can be mounted in buildings of any type, does not require special aft passages, combines loading and unloading operations with transportation, regardless of the presence of access roads, and improves work culture. The unit uses a new energy-saving rotary feed pump with a feeder, which allows transporting feed mixtures of high concentration and low humidity. The use of a small-sized unit at small pig farms allows to reduce the metal consumption by 2 times, the energy consumption of the technological process by at least 3.5 times and to increase labor productivity by 2 times in comparison with existing feed shops.

Known pump for feeding liquid feed, containing a housing with two mounted in it on the rotor pins with feed elements, and the inlet and outlet pipes connected respectively to the mixer of liquid feed mixtures and the feed dispensing unit [13]. The disadvantage of the known pump is that when the feed mixtures are supplied with low humidity, the pump flow 
rate sharply decreases due to the deterioration of its suction capacity. This leads to overloading of the feed device, intermittent clogging or complete interruption of the supply of liquid feed mixtures. To restore the transportable ability of the pump, the device resorts to diluting the treated feed mixture with water. However, this reduces the nutritional value of feed for the animal, which in turn negatively affects their productivity.

The closest in technical essence to the proposed one is a pump (feeder) for supplying liquid feed, containing a housing, two rotors installed in it with feed elements and inlet and outlet nozzles $[14,15]$. The disadvantage of this pump is that when feeding liquid feed mixtures, the main parameters: flow, discharge pressure, volumetric efficiency (efficiency) of the pump deteriorates sharply due to leakage of the pumped mass (feed mixture) from the discharge cavity into the suction cavity. Therefore, the actual pump flow is always less than the theoretical one. Leaks of feed mixture occur through the gaps between the cylindrical surfaces of the housing bore and the outer surfaces of the rotor blade heads, through the end gaps and contact leaks between the rotors. Among these leaks, the main ones are leaks of feed mixture from the discharge chamber to the suction chamber between the rotors. The values of the remaining leaks with an increase in the viscosity of feed mixtures over $0.8 \mathrm{~Pa} / \mathrm{s}$ are insignificant [16,17].

Taking into account the above disadvantages of existing pumps, we have developed an improved feed pump for feeding liquid feed, containing a housing with two assembled rotors with lamellar feed elements installed in it, inlet and outlet pump nozzles connected, respectively, to a mixer of initial feed components and a feed dispensing unit, to increase reliability in operation and improvement of the pump performance, the modular rotors are located in the housing with an eccentricity. Plates with springs are installed in the radial slots of the rotors. The plates pressed against the body and rotating together with the rotors slide along the inner cylindrical surface of the body, simultaneously reciprocating with respect to the rotor in its slots. The initial clamping of the plates in the pump is carried out under the action of centrifugal force and springs, and the working clamp is produced under the action of the hydrostatic pressure of the liquid (feed mixture) on the inner ends of the plates from the rotor slot.

Due to the eccentricity of the rotors, when the plates move away from the point where the distance between the rotors and the casings is minimal, the volume between the plates (the volume of the pump working chamber) increases.

As a result, the filling of the pump working chamber with feed mixtures supplied through the pump suction pipe is improved. When the plates pass into the discharge cavity, the volume of the pump working chamber gradually decreases. This increases the density of the feed mixture in the pump working chamber, which increases the pump discharge pressure. In addition, an increase in the density of the pumped medium in the working chamber of the pump eliminates cavitation and pump vibration, i.e. increases the reliability of the pump in operation. The implementation of the feeding elements in the form of plates, reciprocating relative to the rotor in its slots, allows to reduce the distance (gap) between the rotors, as well as the gap of the inner bore of the cylindrical surface of the housing with the outer surfaces of the heads of the rotor plates. This stops leaks from the discharge chamber to the suction chamber, which increases the pump flow.

To reduce the contact forces between the sliding edges of the plates and the inner surfaces of the casing bores, the pump uses hydrostatic unloading in the form of semicircular grooves in the casing end caps. Weakening the bending of the plates can be achieved by tilting the plates in the direction of rotation through an angle $\alpha$ (usually $\alpha=15^{\circ}$ ). 


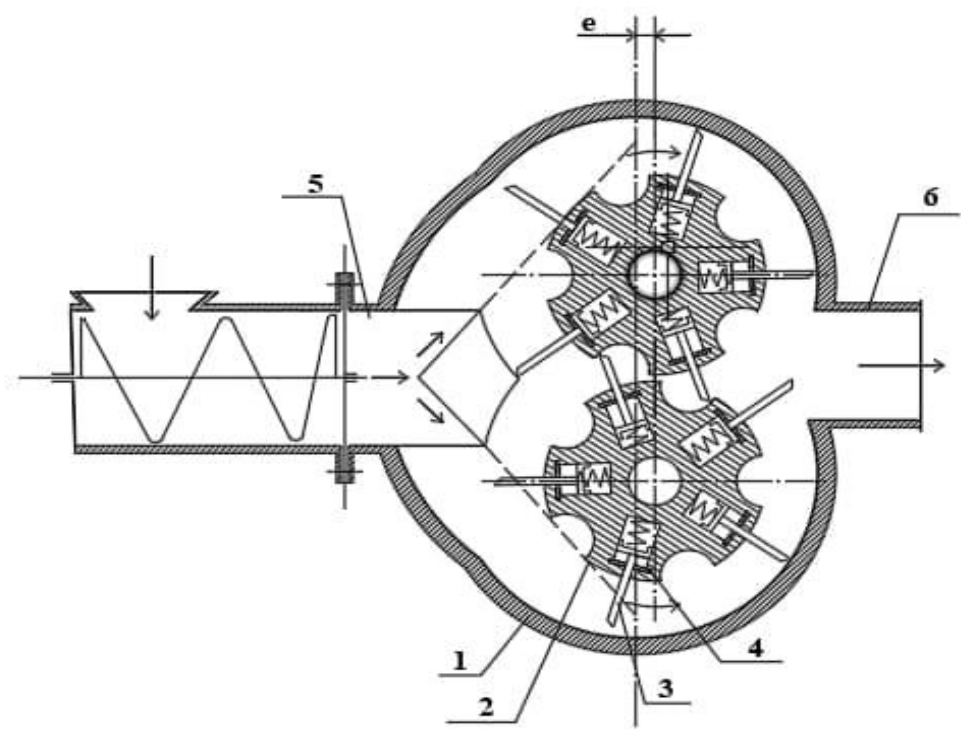

Fig. 1. Improved pump for low moisture liquid feed; 1-building; 2-rotor; 3-plates; 4 springs; 5-inlet pipe; 6-discharge branch pipe

Semicircular recesses in the rotors reduce the inter-rotor distance.

The pump for supplying liquid feed mixtures of low humidity consists of a housing 1 , rotors 2 , plates 3 , springs 4 , inlet 5 and delivery 6 nozzles. The main parts of the pump are assembled rotors 2 , rotating at the same angular velocity, but in opposite directions. Rotors 2 are placed in the housing 1 with displacement 1 from the center of the circumference of the inner cylindrical surface of the housing towards the discharge pipe 6 . In the radial grooves of the rotor 2 plates 3 with springs are installed 4 . The plates 3 pressed against the housing 1 and rotating together with the rotors 2 slide along the inner surface of the housing 1 , while simultaneously reciprocating relative to the rotor in its slots.

The pump works as follows. The liquid feed mixture coming from the inlet pipe 5 of the pump housing 1 is carried by the plates 4 in the direction of rotation of the rotors 2 . Then, when the plates 3 enter the discharge cavity, the volume of the space between the plates 3 gradually decreases, and the filling factor of the pump working chambers increases. After moving the cut off volume into the discharge chamber, the plates 3 meet the opposite rotors 2 . When the rotors 2 turn, the plates 3 enter the grooves of the rotor 2, thereby ensuring the separation of the suction cavity from the discharge cavity. This completely stops the leaks of feed mixture from the discharge chamber into the suction chamber. An increase in the filling factor of the working chambers of the pump increases the pump discharge pressure, and an increase in the density of the feed mixture in the working chambers eliminates cavitation and vibration of the pump, i.e. increases the reliability of the pump in operation.

The main calculated technological and energy indicators of the pump: flow rate-30m 3 / $\mathrm{h}$, discharge pressure $-0.4 \mathrm{MPa}$, pump rotor speed $200 \mathrm{~min}-1$, required power $-6 \mathrm{~kW}$, specific energy consumption of the technological process no more than $-0.21 \mathrm{kWh} / \mathrm{m} 3$, the cost of working time for the execution of the technological process $-0.034 \mathrm{~h}$. 
The application of this improved pump in farm production requires careful learning. This requires the use of the most innovative [18,19] and modern pedagogical [20] technologies of teaching, online training of farmers and telecommunication training projects [21]. In such teaching, lectures are not in a simple traditional form but are problematic and modern lectures $[22,23,24]$ should be conducted using interactive methods, ensuring the activity of the audience. At the same time, of course, it is important to address the audience with problematic questions during the lesson, to direct them to creative and scientific thinking by creating problematic situations in the lecture. In addition, the creation of online training courses, including the use of technologies such as project style [25], scientific and creative thinking, enriching the online course module platform with electronic resources [26], including video and audio lectures, gives great results. In short, there is a need to pay more attention to education in the use of improved pumps on farms. It is no coincidence that the quality of education is the quality of life $[27,28,29]$.

\section{Conclusions}

1. It is advisable to transport and distribute feed mixtures of low moisture content on farms and small farms using pipeline transport with pumping units. At the same time, the cost of working time is reduced by $4 \ldots 5$ times compared to mobile distributors.

2. Existing centrifugal and fecal pumps are ineffective for transporting low moisture feed mixtures, which include juicy and green feed. These pumps can be used to deliver feed mixtures with a moisture content of $73 \%$ or more without the inclusion of juicy green feed. This is due to the fact that the transportable ability of feed mixtures is significantly impaired when a paste from juicy green feed is introduced into their composition. At the same time, the mixture thickens, its fluidity decreases, the viscosity and pressure losses in the feed line increase by $2 \ldots 3$ times.

3. Transportation of low-moisture feed mixtures, which include juicy green feed, on farms and small farms, it is advisable to carry out volumetric pumps with forced (rotary, vane, rotary, gear, piston, etc.) power supply.

4. The proposed design of the pump works most steadily when feeding feed mixtures of low humidity, which include juicy green feed.

5. On the basis of the improved pump, a small-sized universal unit for preparation, transportation, and distribution of feed mixtures has been developed. All equipment included in the universal modernized avao, taking into account the characteristics of farms. Unit productivity: for mixing - $1.0 \mathrm{t} / \mathrm{h}$; for dispensing $-30 \mathrm{t} / \mathrm{h}$, installed capacity $-22 \mathrm{~kW}$. The use of this unit on farms and small farms can reduce the cost of working time by 5 times compared to a mobile dispenser.

6. The use of the new pump on farms allows to reduce the metal content by 2 times, the energy consumption of the technological process by at least 3.5 times and increase the productivity by 2 times in comparison with the existing centrifugal pumps.

\section{References}

1. Kryshtop E.A. Improving the productive qualities of pigs by mobilizing the internal reserves of the body: doct. dis. Biological Sciences. Volgograd, 2011.P-465.

2. Knyazev K.I. Intensive meat feeding of pigs. M.: Kolos, 1979.P-222.

3. Devyatkin A.I. Rational use of feed in industrial production. M.: Rosselkhozizdat, 2016. P-345. 
4. Boyarsky L.G. Production and use of feed in industrial production. M.: Rosselkhozizdat, 2018. P-542.

5. Scientific foundations of complete feeding of farm animals. Sat scientific works. M .:, Agopromizdat, 2017. P-145.

6. A.A. Utkin. Pig feeding systems. Monograph. Podolsk, gnu VNIIMZh Russian Agricultural Academy. 2011.226s. ["Electronic resource] / URL: https://animalration.ru/wp-content/uploads/2019/02/utkin (date of access: 24.09.2020)

7. Abduosiev, F. Prospects for the development of animal husbandry taking into account scientific and technological progress [Electronic resource] / F. Abduosiev // Internetversion of the publications of CharkhiGardun LLC. - 25.10 2012.- Access mode: http: //www.gazeta.tj/dp/5936-perspektivy-razvitiya-zhivotnovodstva-s-uchetom-nauchnotexnicheskogo-progressa.html

8. Gubeidullin Kh.Kh. Improvement of technologies and means of mechanization of distribution of liquid and semi-liquid feed: dis .... Doctor of Technical Sciences, Ulyanovsk, 2005.351 p. ["Electronic resource] .URL: https://www.dissercat.com/content/tekhnologiya-peremeshcheniya-sypuchikh-izhidkikh-selskokhozyaistvennykh-materialov-spiralno. (date of request: 24.09.2020)

9. Baxter M.R. Design of new feeder for pigs // Farm Building Progress. 1989.96.: P-1922.

10. Roth E. HachlesefiirSauenhalter und SchweinmasterAgrar. Ubers. 1989. 40 N 9. P-6669

11. Alexandrov V.I. Methods for reducing energy consumption in the hydraulic transport of high concentration mixtures. SPb.: SPGGI (TU), 2000, P-117.

12. Dokukin V.P. Improving the efficiency of the pipeline hydro transport system, St. Petersburg, SPGGI (TU), 2005, P-105.

13. Bazarov D, Vatin N, Bakhtiyor O, Oybek V. Hydrodynamic effects of the flow on the slab of the stand in the presence of cavitation. IOP Conf Ser Mater Sci Eng. 2021;1030:012110.

14. Klimov V.I. Rotary lobe pumps for high-viscosity dairy products. M .:, 1970.

15. Rakhimov O.D., Khudoyorov B.M. Mamatov F.M. Ergashev I. Pump for the supply of liquid feed mixtures. / a.s. 1089. Patent 5149 Resb. Uzbek. 03.07.1998.

16. Rakhimov O.D., Khudoyorov B.M. Mamatov F.M. Eshkobilov U.B. Feed pump. // a.s. 1090. Patent 5150 Rep. Uzbek. 17.07.1998

17. Bazarov D, Vatin N, Bakhtiyor O, Oybek V. Hydrodynamic effects of the flow on the slab of the stand in the presence of cavitation. IOP Conf Ser Mater Sci Eng. 2021;1030:012110.

18. Rakhimov O.D., TogaevZh.Kh., KhuzhakulovA.Kh. Improved feed pump for farms. / Akademy. 2019. № 6 (45). P-25-27.

19. Dilshod B, Markova I, Sultanov S, Kattakulov F. Dynamics of the hydraulic and alluvial regime of the lower reaches of the Amudarya after the commissioning of the Takhiatash and Tuyamuyun hydrosystems. IOP Conf Ser Mater Sci Eng. 2021;1030:012110.

20. Rakhimov O.D., Manzarov Y.K., Karshiyev A.E. Klassifikatsiya pedagogicheskikh tekhnologiy i tekhnologiya problemnogo obucheniya. //Problemy sovremennoy nauki i obrazovaniya, 2020.№2(147). C.59-62. DOI c 10.24411/2304-2338-2020-10201.

21. Khidirov S, Jumaboeva G, Ishankulov Z. Hydraulic mode of operation of the Takhiatash hydroelectric complex. 2021; 
22. O.D Raximov, B.F Nazarov, M.S Sapaev. Modern lectures in higher education. // TUIT Karshi branch, 2012

23. Raximov O.D. Innovative pedagogical technologies: project style as a technology that improves the quality of education. // Karshi, TUIT Karshi branch, 2013., P- 80.

24. Obidov B, Vokhidov O, Tadjieva D, Saidkhodjaeva D, Kurbanova U, Isakov A. Hydrodynamic effects on the flow elements of the downstream devices in the presence of cavitation. IOP Conf Ser Mater Sci Eng. 2021;1030:012114.

25. Raximov O.D. Requirements and technology for creating e-learning resources. // Sovremennoe obrazovane (Uzbekistan). 2016, 202. P-45-50

26. Uralov B, Rakhmatov N, Khidirov S, Safarov G. Hydraulic modes of damless water intake. 2021;

27. Raximov O.D.,Manzarov Y.Kh.,Keldiyarova M., Xudjakulov A.H. Modern lectures and methods of organizing problematic lectures. // Журнал "Проблемы науки". 2020.№2(50). C.45-48. DOI 10.24411/2413-2101-2020-10201

28. Raximov O.D. Quality of education-quality of life. Karshi branch of Tashkent University of Information Technologies, 2015. P-46

29. Uralov B, Rakhmatov N, Khidirov S, Safarov G. Hydraulic modes of damless water intake. 2021;

30. S.Eshev, Sh. Latipov, A.Qurbonov, J. Sagdiyev, M. Berdiev ,N. Mamatov. Noneroding speed of water flow of channels running in cohesive soils. Intedration, Partnership. Innovationm in construction science-education (IPICSE 2020). 2020 y. 1114 november. IOP Conf. Series: Materials Science and Engineering 1030 (2021) 012131. IOP Publishing. doi:10.1088/1757-899X/1030/1/012131

31. Matyakubov B, Begmatov I, Raimova I, Teplova G. Factors for the efficient use of water distribution facilities. IOP Conf Ser Mater Sci Eng. 2020;883:012025.

32. S.Eshev ,A. Rakhimov1, I. Gayimnazarov, A.Isakov1, B.Shodiev, F.Bobomurodov. Dynamically stable sections of large soil canals taking into account wind waves. Intedration, Partnership. Innovationm in construction science-education (IPICSE 2020). 2020 y. 11-14 november. IOP Conf. Series: Materials Science and Engineering 1030 (2021) 012131. IOP Publishing. doi:10.1088/1757-899X/1030/1/012131 